Check for

Cite as

Nano-Micro Lett.

(2020) 12:128

Received: 11 March 2020

Accepted: 18 May 2020

Published online: 16 June 2020

(C) The Author(s) 2020

\section{MXene-Derived Defect-Rich $\mathrm{TiO}_{2} @$ rGO as High-Rate Anodes for Full Na Ion Batteries and Capacitors}

\author{
Yongzheng Fang ${ }^{1}$, Yingying Zhang ${ }^{1}$, Chenxu Miao ${ }^{1}, \mathrm{Kai}_{\mathrm{Zhu}}{ }^{1}{ }^{凶}$, Yong $\mathrm{Chen}^{2}$, Fei Du ${ }^{3}$, \\ Jinling Yin ${ }^{1}, \mathrm{Ke} \mathrm{Ye}^{1}$, Kui Cheng ${ }^{1}$, Jun Yan ${ }^{1}$, Guiling Wang ${ }^{1}$, Dianxue Cao ${ }^{1 凶}$ \\ $\triangle$ Kai Zhu, kzhu@hrbeu.edu.cn; Dianxue Cao, caodianxue@hrbeu.edu.cn \\ 1 Key Laboratory of Superlight Materials and Surface Technology (Ministry of Education), College \\ of Material Science and Chemical Engineering, Harbin Engineering University, Harbin 150001, \\ People's Republic of China \\ 2 State Key Laboratory of Marine Resource Utilization in South China Sea, Hainan Provincial Key Laboratory \\ of Research on Utilization of Si-Zr-Ti Resources, College of Materials Science and Engineering, Hainan \\ University, 58 Renmin Road, Haikou 570228, People's Republic of China \\ 3 Key Laboratory of Physics and Technology for Advanced Batteries (Ministry of Education), College \\ of Physics, Jilin University, Changchun 130012, People's Republic of China
}

\title{
HIGHLIGHTS
}

- A freestanding $\mathrm{MXene-derived} \mathrm{defect-rich} \mathrm{TiO}_{2} @$ reduced graphene oxides $\left(\mathrm{M}-\mathrm{TiO}_{2} @ \mathrm{rGO}\right)$ foam electrode was fabricated.

- $\mathrm{M}-\mathrm{TiO}_{2} @ \mathrm{rGO}$ presents fast $\mathrm{Na}^{+}$storage kinetics due to capacitive contribution.

- $\quad \mathrm{M}-\mathrm{TiO}_{2} @ \mathrm{rGO}$ foam electrode displays a capacity retention of $90.7 \%$ after 5000 cycles.

\begin{abstract}
Sodium ion batteries and capacitors have demonstrated their potential applications for next-generation low-cost energy storage devices. These devices's rate ability is determined by the fast sodium ion storage behavior in electrode materials. Herein, a defective $\mathrm{TiO}_{2} @$ reduced graphene oxide $\left(\mathrm{M}-\mathrm{TiO}_{2} @ \mathrm{rGO}\right)$ self-supporting foam electrode is constructed via a facile MXene decomposition and graphene oxide self-assembling process. The employment of the MXene parent phase exhibits distinctive advantages, enabling defect engineering, nanoengineering, and fluorine-doped metal oxides. As a result, the M-TiO ${ }_{2} @$ rGO electrode shows a pseudocapacitance-dominated hybrid sodium storage mechanism. The pseudocapacitance-dominated process leads to high capacity, remarkable rate ability, and superior cycling performance. Significantly, an $\mathrm{M}-\mathrm{TiO}_{2} @ \mathrm{rGO} / / \mathrm{Na}_{3} \mathrm{~V}_{2}\left(\mathrm{PO}_{4}\right)_{3}$ sodium

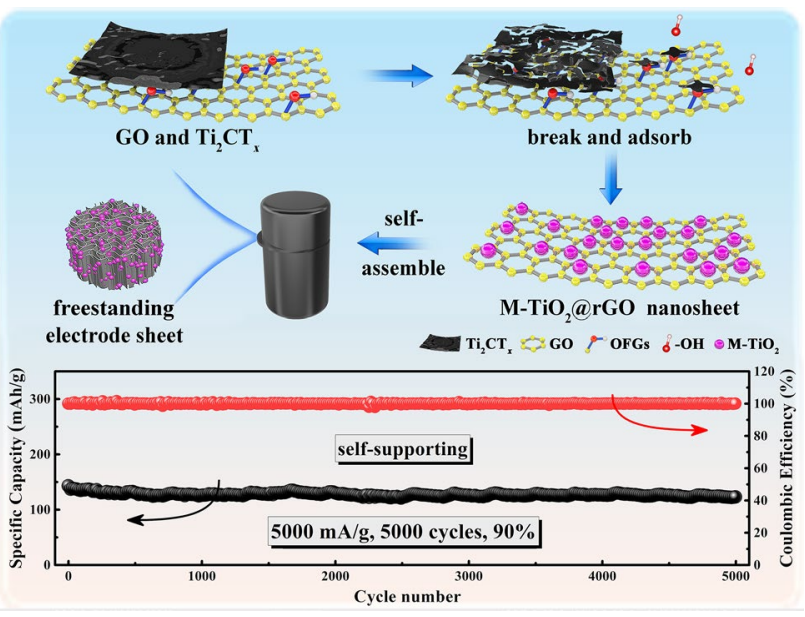
full cell and an $\mathrm{M}-\mathrm{TiO}_{2} @ \mathrm{rGO} / / \mathrm{HPAC}$ sodium ion capacitor are fabricated to demonstrate the promising application of $\mathrm{M}-\mathrm{TiO}{ }_{2} @ \mathrm{rGO}$. The sodium ion battery presents a capacity of $177.1 \mathrm{mAh} \mathrm{g}^{-1}$ at $500 \mathrm{~mA} \mathrm{~g}^{-1}$ and capacity retention of $74 \%$ after 200 cycles. The sodium ion capacitor delivers a maximum energy density of $101.2 \mathrm{Wh} \mathrm{kg}^{-1}$ and a maximum power density of $10,103.7 \mathrm{~W} \mathrm{~kg}^{-1}$. At $1.0 \mathrm{~A} \mathrm{~g}-1$, it displays an energy retention of $84.7 \%$ after 10,000 cycles.
\end{abstract}

KEYWORDS MXene- $\mathrm{Ti}_{2} \mathrm{CT}_{x}$; Vacancy oxygen; Self-supporting; $\mathrm{TiO}_{2}$ anodes; Sodium ion battery and capacitor 


\section{Introduction}

With the high-speed development of electric vehicles and smart grids, the market for electrochemical energy storage devices (EESDs) is bound to expand rapidly [1]. Due to the shortage of lithium resources, lithium-ion batteries are facing the difficulties of increasing cost and future availability [2]. Therefore, sodium ion batteries (SIBs) have attracted great interest due to their low cost and high sodium abundance [3, 4]. To date, $\mathrm{Na}_{3} \mathrm{~V}_{2}\left(\mathrm{PO}_{4}\right)_{3}$ with sodium super ionic conductor (NASICON) structure has been regarded as one of the most promising cathodes [5, 6]. Although NASICONtype cathodes promise fast sodium ion diffusion and highpower density, the rate performance of sodium ion full cells is hindered by the anode materials. Recently, a hybrid device called sodium ion capacitor (SIC) [7, 8] has offered another choice for EESDs, owing to its comprehensive advantages of high energy and power densities. Usually, a SIC consists of a battery-type anode and a capacitor-type cathode to bridge the strengths of SIBs and supercapacitors [9]. The key to constructing a high-performance SIC is to couple a suitable anode with a cathode, wherein they need well match in rate abilities. Thus, anode materials with fast sodium storage kinetics have become a key limitation in developing superior rate performance SIBs and SICs compared to fast energy storage cathodes.

According to the working principles, anode materials can be divided into intercalation, alloying, and conversion types $[10,11]$. Usually, intercalation-type anodes avoid damaging volume expansion and contraction, which is a perplexing problem in alloying and conversion-type anodes [12]. Thus, various intercalation-type anodes have been explored for SIBs, such as hard carbon [13], layered titanium-based oxides [14], and molybdenum-based material [10]. Among these, $\mathrm{TiO}_{2}$ is considered to be one of the most promising SIB anode materials due to its safety and low work potential relative to the $\mathrm{Na}^{+} / \mathrm{Na}$ redox couple $[15,16]$. However, its electrochemical performance is severely restricted by poor electron mobility $\left(\sim 10^{-12} \mathrm{~S} \mathrm{~cm}^{-1}\right)$ and low sodium ion diffusivity $[9,17]$. Defect engineering plays an important role in improving the physical and chemical properties of metal oxides. Oxygen vacancies have recently been shown to be able to significantly enhance the electronic and ionic conductivity of $\mathrm{TiO}_{2}$, thus enhancing the ions storage capacity and catalytic performance [18-20]. Theoretical calculations also indicate that oxygen vacancies can increase the number of reactive sites, decrease the reaction barrier, and improve the ionic diffusion path $[19,21]$. Thus, it is an effective approach to improve the properties of $\mathrm{TiO}_{2}$. Another strategy, preparing nanomaterials has presented a unique advantage in shortening the sodium ion transport pathway [9, 22]. Ti-based MXene materials have been reported as a capable precursor for producing nano-Ti-based oxides and related composites owing to its two-dimensional (2D) nanosheet morphology [15, 23, 24]. However, the details of the transformation from Ti-based MXene to Ti-based oxide and the cause of MXene's instability in the water have been unclear. 2D materials were often employed to carry nanomaterials due to the large specific surface and fast ions/electrons diffusion [25-27]. Moreover, modification with carbon-based materials has been shown to be an effective solution for enhancing electron transport to achieve a high rate anode material [28, 29]. Recently, introducing a capacitive contribution has demonstrated another effective approach for overcoming poor sodium ion diffusion [7, 15, 23]. Designing defective nanomaterials can extremely enhance the capacitive contribution, leading to impressive rate performance and cycling stability [30, 31].

The architectural design of electrodes plays an important role in the performance and processing cost of batteries. Usually, the electrode is fabricated by a tedious slurrycasting process [32]. In a toxic and costly $\mathrm{N}$-methyl pyrrolidone (NMP), the mixture of electrode materials including a conductive additive $(\sim 10 \mathrm{wt} \%)$ and an insulating binder $(\sim 10 \mathrm{wt} \%)$ is cast onto a heavy metal current collector. Inactive components occupy $70-80 \mathrm{wt} \%$ of the whole electrode, which significantly reduces the energy density and increases the cost $[8,33]$. Thus, freestanding and binder-free construction could eliminate the additional inactive materials to realize a high-efficiency electrode.

Herein, a freestanding, binder-free, and defective $\mathrm{Ti}_{2} \mathrm{CT}_{x}-\mathrm{MXene-derived} \mathrm{TiO}_{2}$ complex reduced graphene oxides $\left(\mathrm{M}-\mathrm{TiO}_{2} @ \mathrm{rGO}\right) 3 \mathrm{D}$ foam electrode was designed and synthesized via a simple and nontoxic hydrothermal process. $\mathrm{Ti}_{2} \mathrm{CT}_{x}-\mathrm{MXene}$ was converted to $\mathrm{M}-\mathrm{TiO}_{2}$ by consuming the $-\mathrm{OH}$ in the $\mathrm{H}_{2} \mathrm{O}$ and the $\mathrm{F}$ functional group self-doped into the $\mathrm{M}-\mathrm{TiO}_{2}$, during that a large number of lattice defects and oxygen vacancies were generated in situ. The addition of graphene oxide promoted the above reaction and constructed a 3D $\mathrm{M}-\mathrm{TiO}_{2} @$ graphene composite with a highly conductive pathway 
and accelerated ion diffusion. Directly employed as the anode for a sodium ion half-cell, the prepared materials displayed a remarkable rate ability and stable cycling performance due to its large capacitive contribution. Significantly, this composite was a capable and universal anode for both sodium ion full cells and sodium ion capacitors with favorable cycling stability.

\section{Experimental Section}

\subsection{Preparation of $\mathrm{Ti}_{2} \mathrm{CT}_{x}$ MXene Powder}

$\mathrm{Ti}_{2} \mathrm{CT}_{x}$ MXene was obtained by a synthetic HF solution. Specifically, $3 \mathrm{~g}$ of LiF (Alfa Aesar, 98.5\%) was dissolved in $30 \mathrm{~mL} \mathrm{HCl}\left(12 \mathrm{M}\right.$ ). Then $2 \mathrm{~g}$ of $\mathrm{Ti}_{2} \mathrm{AlC}$ (200 mesh, purchased from Forsman Scientific (Beijing) Co., Ltd.) powder was slowly added into the above mixture solution and kept at $40{ }^{\circ} \mathrm{C}$ for $36 \mathrm{~h}$ under stirring. After that, the solution was centrifuged several times until the $\mathrm{PH}$ of the supernatant was about 5-6. Particularly, the supernatant of the first centrifuge was khaki. Finally, $\mathrm{Ti}_{2} \mathrm{CT}_{x}$ cake resembling graphene oxide was obtained by freeze-dried.

\subsection{Preparation of $\mathrm{M}-\mathrm{TiO}_{2} @$ rGO Foam, $\mathrm{M}-\mathrm{TiO}_{2}$, $\mathrm{Na}_{3} \mathrm{~V}_{2}\left(\mathrm{PO}_{4}\right)_{3}$, and HPAC}

M-TiO $\mathrm{T}_{2} @ \mathrm{rGO}$ foam was prepared through a simple hydrothermal reaction [15]. In the typical preparation, $120 \mathrm{mg}$ $\mathrm{Ti}_{2} \mathrm{CT}_{x}$ was dissolved in $40 \mathrm{~mL}$ distilled water and ultrasound for $3 \mathrm{~h}$, then $130 \mathrm{mg}$ GO (prepared from a modified Hummers method [34]) was added in it and continued ultrasound for $2 \mathrm{~h}$. After that, $4 \mathrm{~mL} \mathrm{NaHSO}$ ( $0.5 \mathrm{mM})$ solution was added to the above solution as a reducing agent. Finally, the above solution was transferred to a polytetrafluoroethylene reactor and kept at $180{ }^{\circ} \mathrm{C}$ for $16 \mathrm{~h}$. The obtained

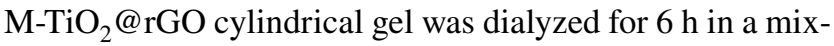
ture of water and ethanol. Finally, the M-TiO $@$ rGO foam was obtained through a freeze-drying process.

$\mathrm{M}-\mathrm{TiO}_{2}$ nanoparticles were prepared under the same conditions without the addition of GO.

$\mathrm{Na}_{3} \mathrm{~V}_{2}\left(\mathrm{PO}_{4}\right)_{3}$ cathode material was prepared by the previous report [5].

3D hierarchical porous activated carbon (HPAC) derived from coir was prepared by the previous report [35].

\subsection{Material Characterizations}

The compositions of $\mathrm{M}-\mathrm{TiO}_{2} @ \mathrm{rGO}$ and $\mathrm{M}-\mathrm{TiO}_{2}$ were characterized by X-ray diffractometer (XRD) with copper $\mathrm{K} \alpha$ radiation $(\lambda=1.5418 \AA)$ and Raman spectroscopy (RENISHAW, REF 2000, $514.5 \mathrm{~nm}$ laser). The surface functional groups of $\mathrm{M}-\mathrm{TiO}_{2} @ \mathrm{rGO}$ were checked by XPS (Axis Ultra DLD, Kratos Analytical). The morphologies of the $\mathrm{M}-\mathrm{TiO}_{2} @ \mathrm{rGO}, \mathrm{M}-\mathrm{TiO}_{2}$, and $\mathrm{Ti}_{2} \mathrm{CT}_{x}$ were analyzed by a field-emission scanning electron microscope (SEM, JEOL, JSM7500F) and a transmission electron microscope (TEM, JEOL, JEM-2100 model). Nitrogen adsorption-desorption isotherms were tested on a Quantachrome NOVA 2000e sorption analyzer at $77 \mathrm{~K}$ with liquid nitrogen. The rGO content of samples was tested by thermogravimetry (TAInstruments-Wutersllc, TGA 500). The oxygen vacancies were checked through the electron paramagnetic resonance (EPR) spectra, which were recorded on a Bruker EPR ELEXSYS 500 spectrometer.

\subsection{Fabrication and Electrochemical Measurements of Half Cells}

The self-supporting $\mathrm{M}-\mathrm{TiO}_{2} @ \mathrm{rGO}$ electrode sheets were obtained after freeze-drying the sheets cut from $\mathrm{M}-\mathrm{TiO}_{2} @$ rGO gel (when it was wet). The coated $\mathrm{M}-\mathrm{TiO}_{2} @ \mathrm{rGO}$, HPAC, or NVP working electrodes consisted of active materials, supper $\mathrm{P}$, and polyvinylidene fluoride (PVDF) (80:10:10 wt \%), which were dispersed in $N$-methyl-

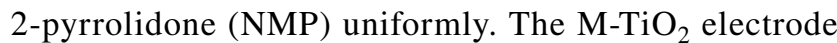
was 70:20:10 wt\% to balance its carbon-free nature. The slurry was coated on the current collectors $(\mathrm{Cu}$ foils for $\mathrm{M}-\mathrm{TiO}_{2}, \mathrm{M}-\mathrm{TiO}_{2} @ \mathrm{rGO}$ anodes, and $\mathrm{Al}$ foils for HPAC, NVP cathodes) and dried at $80{ }^{\circ} \mathrm{C}$ in vacuum for $24 \mathrm{~h}$. And then, these coated electrodes were cut into a circular shape with diameters of $12 \mathrm{~mm}$. The mass loading was $0.5-1 \mathrm{mg} \mathrm{cm}^{-2}$ for anodes and $1-2 \mathrm{mg} \mathrm{cm}^{-2}$ for cathodes. In an Ar-filled glove box, CR2023-type coin cells were assembled with the as-prepared electrodes as working electrodes, the metallic sodium as the counter electrode and reference electrode, the glass fibers (Whatman) as separators, and the $1.0 \mathrm{M} \mathrm{NaClO}_{4}$ in EC: DMC: $\mathrm{EMC}=1: 1: 1$ vol\% with $5.0 \%$ FEC as the electrolyte. The constant current charge/discharge tests were measured 
at the NEWARE battery test system (CT-4008 model), and the cyclic voltammetry (CV) tests were performed at Bio-Logic VMP3 electrochemical workstation. All electrochemical measurements were tested at room temperature. The specific capacities and current densities of self-supporting $\mathrm{M}-\mathrm{TiO}_{2} @ \mathrm{rGO}$ electrodes were calculated based on the $\mathrm{M}-\mathrm{TiO}_{2}$ mass (70 wt\%), correspondingly, the coated $\mathrm{M}-\mathrm{TiO}_{2} @ \mathrm{rGO}$ electrodes were calculated based on the $\mathrm{rGO}$ and $\mathrm{M}-\mathrm{TiO}_{2}$ mass $(80 \mathrm{wt} \%$ in the total coating materials). Those in cathode electrodes (HPAC and NVP) were based on the active materials $(80 \mathrm{wt} \%$ in the total coating materials). The voltage ranges of the $\mathrm{M}-\mathrm{TiO}_{2}$, $\mathrm{M}-\mathrm{TiO}_{2} @ \mathrm{rGO}, \mathrm{HPAC}$, and NVP were 0.1-3.0, 0.1-3.0, $3.0-4.2$, and $2.0-4.3 \mathrm{~V}$, respectively.

\subsection{Fabrication and Electrochemical Measurements of Full Cells of SICs and SIBs}

Before assembling the full batteries, the coated $\mathrm{M}-\mathrm{TiO}_{2} @$ rGO was activated for 5 cycles at $50 \mathrm{~mA} \mathrm{~g}^{-1}$ in half cells. In the SICs, HPAC as a cathode and the coated $\mathrm{M}-\mathrm{TiO}_{2} @ \mathrm{rGO}$ as an anode, the mass ratios were 1:1.0, 1:1.5, 1:2.0, 1:3.0 (anode: cathode), and the voltage range was 1.0-4.0 V. In the SIBs, NVP as the cathode and the coated $\mathrm{M}-\mathrm{TiO}_{2} @ \mathrm{rGO}$ as the anode, the mass ratio was optimized at 1:3 (anode: cathode), and the voltage range was $1.0-3.5 \mathrm{~V}$. The separator, electrolyte, and assembly method were the same as those in half cells.

The specific capacities of the SIBs were calculated based on the mass of the coated $\mathrm{M}-\mathrm{TiO}_{2} @ \mathrm{rGO}$.

The energy densities $\left(E, \mathrm{Wh} \mathrm{kg}^{-1}\right)$ and power densities $\left(\mathrm{P}, \mathrm{W} \mathrm{kg}^{-1}\right)$ of the SICs were calculated by Eqs. (1) and (2):

$E=\frac{\int_{t_{1}}^{t_{2}} I V \mathrm{~d} t}{\left(M_{1}+M_{2}\right) * 3.6}$

$P=\frac{E}{T}$

In the formulas, $t_{1}$ and $t_{2}$ are the start and end time (s) of the discharge, respectively, $I(\mathrm{~A})$ is the current, $V(\mathrm{~V})$ is the voltage at a particular time, $M_{1}$ and $M_{2}$ are the mass of anode and cathode $(\mathrm{g})$, respectively, and $T(\mathrm{~h})$ is the total time of the discharge.

\section{Results and Discussion}

\subsection{Synthesis and Characterization of Defective MXene-Derived $\mathrm{TiO}_{2} @$ Graphene Electrode}

$\mathrm{Ti}_{2} \mathrm{CT}_{x}-\mathrm{MXene}$-derived $\mathrm{TiO}_{2}$ complex graphene (M-TiO $\mathrm{T}_{2} @ \mathrm{rGO}$ ) foam was prepared by a simple hydrothermal reaction associated with a series of transformations of $\mathrm{Ti}_{2} \mathrm{CT}_{x}$. First, $\mathrm{Ti}_{2} \mathrm{CT}_{x}$ nanosheets were mixed uniformly with graphene oxide (GO) nanosheets in an ultrasonic process (Fig. 1a). Then, in a hydrothermal process, the $\mathrm{Ti}_{2} \mathrm{CT}_{x}$ nanosheets broken into small lamellae and attached to the surface of GO by the inducing effect of the oxygencontaining function groups (OFGs) of the GO (Fig. 1b). As the reaction continued, the $\mathrm{Ti}_{2} \mathrm{CT}_{x}$ nanosheets gradually crimped, fractured (Fig. 1c), and finally converted into $\mathrm{TiO}_{2}$ nanoparticles (Fig. 1d). Compared to some preparation technologies using harmful organic solvents, this water-based synthetic approach was nontoxic and green. Meanwhile, GO was converted into reduced graphene oxides (rGO) and an $\mathrm{M}-\mathrm{TiO}_{2} @ \mathrm{rGO}$ gel was formed by a self-assembly process (Fig. 1e). As shown in the digital images (Fig. 1g), the obtained $\mathrm{M}-\mathrm{TiO}_{2} @ \mathrm{rGO}$ gel sample supported a $100 \mathrm{~g}$ weight, exhibiting good mechanical character. The gel also exhibited a certain toughness that could be cut into self-supporting electrodes with a thickness of $\sim 0.5 \mathrm{~mm}$. Furthermore, the electrode retained good mechanical properties after drying (Fig. S1). A schematic diagram of the internal structure of the electrode is shown in Fig. 1f, in which a perpendicular porous structure is favorable for electrolyte soaking and enhancing the contact area between electrode and electrolyte, leading to a capable electrochemical performance.

To understand the stability of $\mathrm{Ti}_{2} \mathrm{CT}_{x}$ and the formation mechanism of ${\mathrm{M}-\mathrm{TiO}_{2}}_{2}$ in water, the product and the supernatant after an ultrasonic process were collected and examined. The $\mathrm{pH}$ of the supernatant was about 3-4, which suggested that much $\mathrm{H}^{\cdot}$ was generated and $\mathrm{OH}^{-}$was consumed (Fig. S2). Thus, the formation of $\mathrm{M}-\mathrm{TiO}_{2}$ was mainly caused by the reactions between $\mathrm{Ti}_{2} \mathrm{CT}_{x}$ and $\mathrm{OH}^{-}$produced by the water decomposition, which was accelerated by the applied energy (ultrasonic and thermal energy in this case). Such a reaction might explain the instability of $\mathrm{Ti}_{2} \mathrm{CT}_{x}$ in water and the unsatisfied electrocatalytic performance of $\mathrm{Ti}_{2} \mathrm{CT}_{x}$ in the hydrogen evolution reaction 
(a)

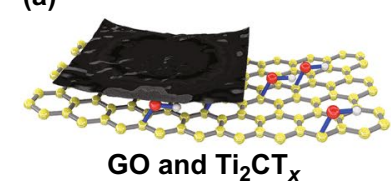

(f)

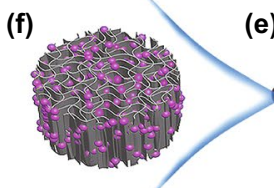

electrode sheet (e)

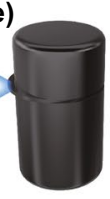

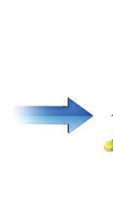

(b)

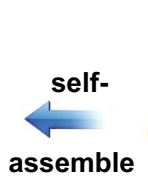

(d)

break and adsorb.

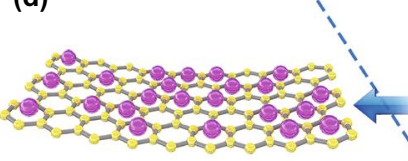

$\mathrm{M}-\mathrm{TiO}_{2} @ \mathrm{rGO}$ nanosheet

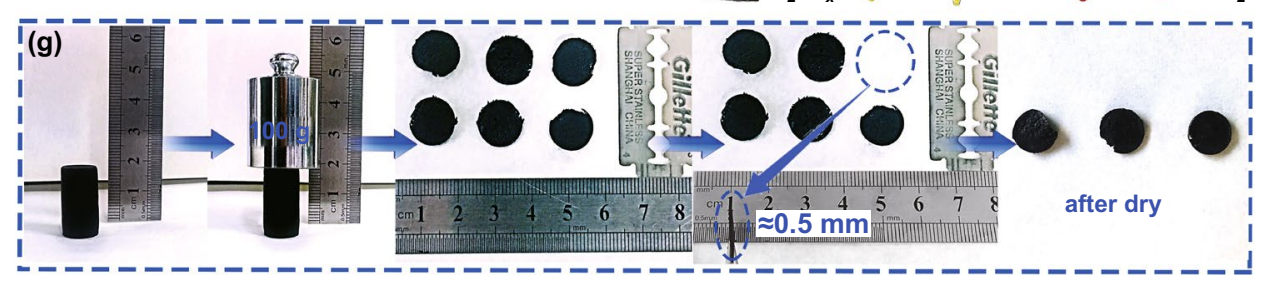

Fig. 1 The schematic and digital pictures of the $\mathrm{M}-\mathrm{TiO}_{2} @ \mathrm{rGO}$ a $\mathrm{GO}$ and $\mathrm{Ti}_{2} \mathrm{CT}_{x}$ nanosheet; $\mathbf{b} \mathrm{Ti}_{2} \mathrm{CT}_{x}$ breaks and adsorbs on OFGs, and then $\mathbf{c}$ through crispation, finally, $\mathbf{d}$ reacts with OFGs and $\mathrm{OH}^{-}$to form $\mathrm{MXene-derived} \mathrm{TiO}_{2} ; \mathbf{e} \mathrm{M}-\mathrm{TiO}_{2} @ \mathrm{rGO}$ nanosheets through self-assemble process come into being composite gel; $\mathbf{f}$ internal structure of self-supporting electrode sheet; and $\mathbf{g}$ physical character of the $\mathrm{M}_{-} \mathrm{TiO}_{2} @ \mathrm{rGO}$ gel and self-supporting electrodes

[36]. Meanwhile, the supernatant was slightly yellow, compared with distilled water (Fig. S2b), which might be caused by suspended carbon nanomaterials derived from $\mathrm{Ti}_{2} \mathrm{CT}_{x}$. Also, transmission electron microscopy (TEM) images of the $\mathrm{Ti}_{2} \mathrm{CT}_{x}$ products after different ultrasonic times showed pure $\mathrm{Ti}_{2} \mathrm{CT}_{x}$ with intact lamellar morphology (Fig. S3a). After $5 \mathrm{~h}$ of sonication, some pores were observed in $\mathrm{Ti}_{2} \mathrm{CT}_{x}$ nanosheets (Fig. S3b). With another $3 \mathrm{~h}$ of sonication, a large proportion of $\mathrm{Ti}_{2} \mathrm{CT}_{x}$ nanosheets cracked into nanoparticles, but a small portion remained in a lamellar state (Fig. S3c). Finally, $\mathrm{Ti}_{2} \mathrm{CT}_{x}$ nanosheets were completely converted into nanoparticles after $10 \mathrm{~h}$ of sonication (Fig. S3d) with $0.35 \mathrm{~nm}$ lattice spacing (Fig. S4), which was assigned to the (101) crystalline plane of anatase- $\mathrm{TiO}_{2}$, suggesting the formation of $\mathrm{TiO}_{2}$ nanoparticles [37]. In addition, the carbon layer could not be observed in the high rate TEM (HRTEM), further suggesting the carbon nanolayer exfoliation. Such a formation process was further confirmed by X-ray diffractometric (XRD) patterns of samples at different reaction times. First, $\mathrm{Ti}_{2} \mathrm{CT}_{x}$ displayed a (002) characteristic peak in place of the highest peak of the $\mathrm{Ti}_{2} \mathrm{AlC}$ at $39.5^{\circ}$, after the removal of $\mathrm{Al}$ layers in the $\mathrm{Ti}_{2} \mathrm{AlC}$ (Fig. S5) [38]. During the ultrasonic process, $\mathrm{Ti}_{2} \mathrm{CT}_{x}$ was converted into an intermediate product with an amorphous phase (after $5 \mathrm{~h}$ sonication) and finally formed the anatase $\mathrm{M}_{-} \mathrm{TiO}_{2}$ (Fig. S6). The microscopic appearance of $\mathrm{M}-\mathrm{TiO}_{2}$ was observed by scanning electron microscopy (SEM), showing serious agglomeration (Fig. S7). Thus, 2D GO nanosheets were necessary because they not only provided much oxygen source and active sites for the formation of $\mathrm{M}-\mathrm{TiO}_{2}$ but uniformly dispersed $\mathrm{M}-\mathrm{TiO}_{2}$ to improve the electrochemical utilization rate.

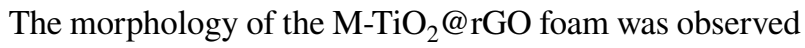
by SEM and TEM, which presented a poriferous honeycomb-like structure composed of numerous $\mathrm{M}-\mathrm{TiO}_{2} / \mathrm{rGO}$ nanosheets (Fig. 2a). On rGO nanosheets, $\mathrm{M}-\mathrm{TiO}_{2}$ nanoparticles cracked from MXene was again confirmed and evenly distributed on the surface (Figs. $2 b$ and S8). This structure of the horizontal arrangement would be beneficial for preserving the sheet structure of graphene and accelerating electronic and sodium ion transportation by the $\mathrm{rGO}$ base. TEM images of $\mathrm{M}-\mathrm{TiO}_{2} @ \mathrm{rGO}$ further confirmed the uniform distribution of $\mathrm{TiO}_{2}$ on the rGO nanosheets (Fig. 2c, d), with an average particle size of $\sim 15 \mathrm{~nm}$, which could shorten sodium ion transportation in the materials. The 

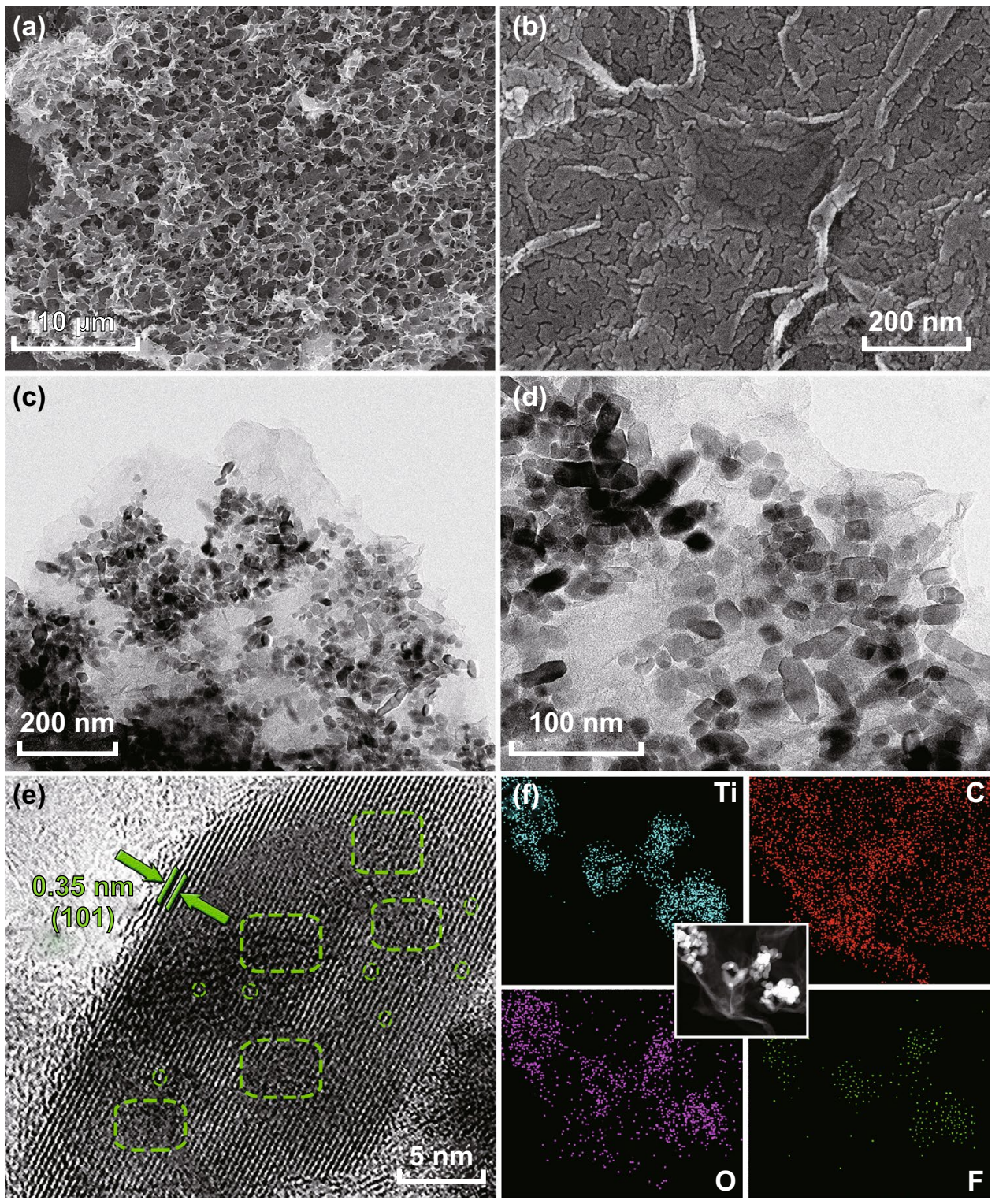

Fig. 2 Microscopic morphology of $\mathrm{M}-\mathrm{TiO}_{2} @ \mathrm{rGO}$ foam. a, b SEM images; c, $\mathbf{d}$ TEM images; e HR-TEM image; and $\mathbf{f}$ dark field TEM and EDS mapping of $\mathrm{C}, \mathrm{O}, \mathrm{Ti}$, and $\mathrm{F}$

small difference in the particle size was attributed to the uneven dissociation of $\mathrm{Ti}_{2} \mathrm{CT}_{x}$ nanosheets. In addition, $\mathrm{rGO}$ had few-layers structure according to the wrinkle thickness and observable lattice fringes (Fig. S9). An HRTEM image displayed clear crystal planes with a $d$-spacing of $0.35 \mathrm{~nm}$, corresponding to the (101) lattice plane of anatase- $-\mathrm{TiO}_{2}$ [37]. Significantly, $\mathrm{M}-\mathrm{TiO}_{2}$ presented a large number of lattice defects with distortion and vacancy (Figs. 2e and S10), which might fundamentally improve the ion/electronic conductivity of $\mathrm{TiO}_{2}$ [31]. Recent studies have also proved that defective engineering was highly beneficial to increasing reactive sites and improving ions diffusion, thereby enhancing electrochemical performance [19, 39]. To further investigate $\mathrm{M}-\mathrm{TiO}_{2} @ \mathrm{rGO}$, EDS was performed, which showed the distribution of $\mathrm{C}, \mathrm{O}$, and $\mathrm{Ti}$ atoms in the composite. Interestingly, $\mathrm{F}$ inherited from $\mathrm{Ti}_{2} \mathrm{CT}_{x}$ surface groups was also observed in composite (Fig. 2f) and pure

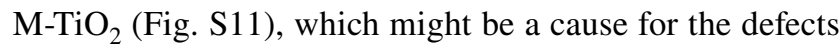
in the $\mathrm{TiO}_{2}$. Moreover, pure anatase $\mathrm{M}-\mathrm{TiO}_{2}$ exhibited a tan color rather than the white of commercial $\mathrm{TiO}_{2}$ (Fig. S12), 
and interestingly, peacock-blue rutile- $\mathrm{TiO}_{2}$ could be also synthesized by adjusting the $\mathrm{pH}$ and controlling the reaction conditions (Fig. S13), which was caused by the oxygen vacancy and heteroatom doping [19, 31, 40, 41].

The structures of $\mathrm{M}-\mathrm{TiO}_{2}$ and $\mathrm{M}-\mathrm{TiO}_{2} @ \mathrm{rGO}$ foam were investigated by XRD (Fig. 3a). Peaks located at $25.3^{\circ}$, $37.8^{\circ}, 48.0^{\circ}, 53.9^{\circ}, 55.0^{\circ}$, and $62.7^{\circ}$ corresponded to (101), (004), (200), (105), (211), and (204) crystal face of anatase $\mathrm{TiO}_{2}$ (PDF\#21-1272), respectively [7, 42]. The hump of $\mathrm{M}-\mathrm{TiO}_{2} @ \mathrm{rGO}$ at $\sim 26^{\circ}$ was enhanced due to the existence of rGO [15]. Using the Scherrer formula based on the XRD results [9], the average crystalline sizes of $\mathrm{M}-\mathrm{TiO}_{2}$ and $\mathrm{M}-\mathrm{TiO}_{2} @ \mathrm{rGO}$ were calculated to be $\sim 18$ and $12 \mathrm{~nm}$, respectively (Table $\mathrm{S} 1$ ). This implied that the addition of rGO limited the $\mathrm{TiO}_{2}$ growth. To further confirm the structure of $\mathrm{M}-\mathrm{TiO}_{2} @ \mathrm{rGO}$, a Raman spectrum was performed (Fig. 3b), in which peaks located at 149, 199, 397, 513, and $639 \mathrm{~cm}^{-1}$ were assigned to the $E_{\mathrm{g}}, E_{\mathrm{g}}, B_{1 \mathrm{~g}}, A_{1 \mathrm{~g}}$, and $E_{\mathrm{g}}$ modes of anatase- $\mathrm{TiO}_{2}$, respectively [15], and the peaks at 1354 and $1600 \mathrm{~cm}^{-1}$ were denoted as the disorder and graphitic peaks (D and $\mathrm{G}$ bands, respectively) [37]. After the hydrothermal reaction, the $I_{\mathrm{D}} / I_{\mathrm{G}}$ of the $\mathrm{M}-\mathrm{TiO}_{2} @ \mathrm{rGO}$ composite (1.01) was higher than that of GO (0.92), which was assigned to the intercalation of ${\mathrm{M}-\mathrm{TiO}_{2}}_{2}$ and nonstacking nature of $\mathrm{M}-\mathrm{TiO}_{2} @ \mathrm{rGO}$ compared to pure graphene [15, 43]. Meanwhile, the content of ${\mathrm{M}-\mathrm{TiO}_{2}}_{2}$ in the composite was found to be $\sim 67 \mathrm{wt} \%$, according to thermogravimetric analysis (TG, Fig. S14). To understand the defect state and F doping, the X-ray photoelectron spectroscopy (XPS) test was performed (Figs. 3c and S15). From Fig. S15b, c, the attachment relation of $\mathrm{M}-\mathrm{TiO}_{2}$ and $\mathrm{rGO}$ was confirmed by the presence of the $\mathrm{Ti}-\mathrm{O}-\mathrm{C}$ bond $[44,45]$. This also indicated that the OFGs on GO was involved in the formation of

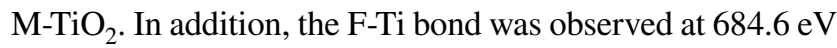
due to F doping (Fig. S15a) [46]. Significantly, the Ti $2 p_{3 / 2}$ and Ti $2 p_{1 / 2}$ core level peaks could be divided into $\mathrm{Ti}^{3+}$ and $\mathrm{Ti}^{4+}$, due to lattice defects $[37,45]$. In the oxygen signal, $530.5 \mathrm{eV}$ could be assigned to lattice oxygen, and the obvious signal at $532.5 \mathrm{eV}$ was caused by oxygen vacancies (Fig. S15c) [21]. Moreover, electron paramagnetic resonance (a)

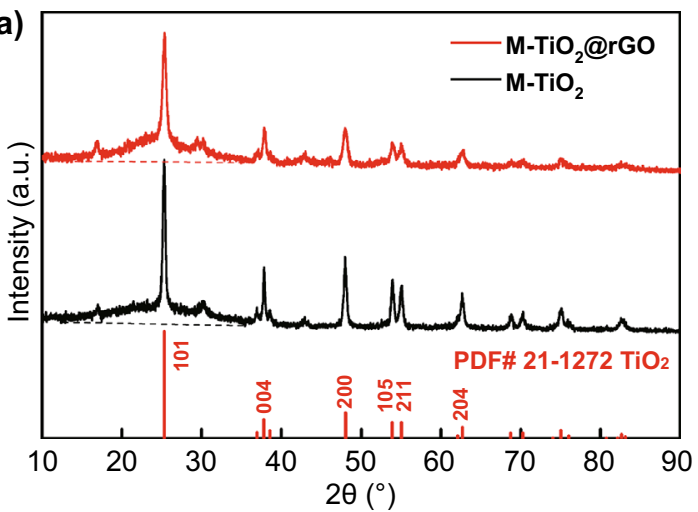

(c)

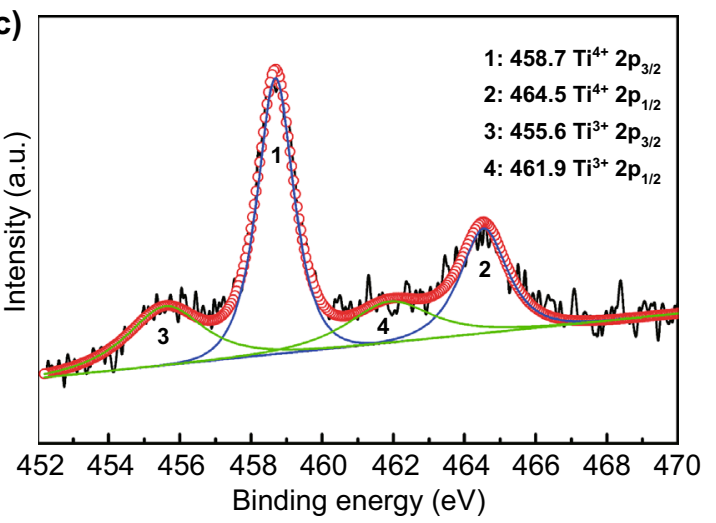

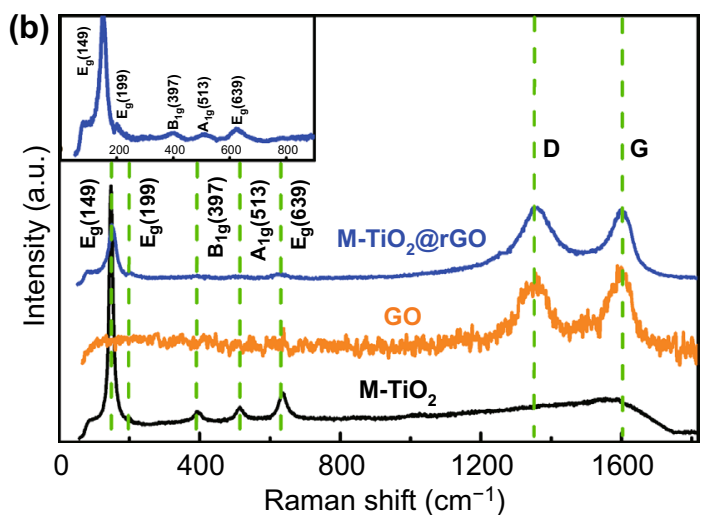

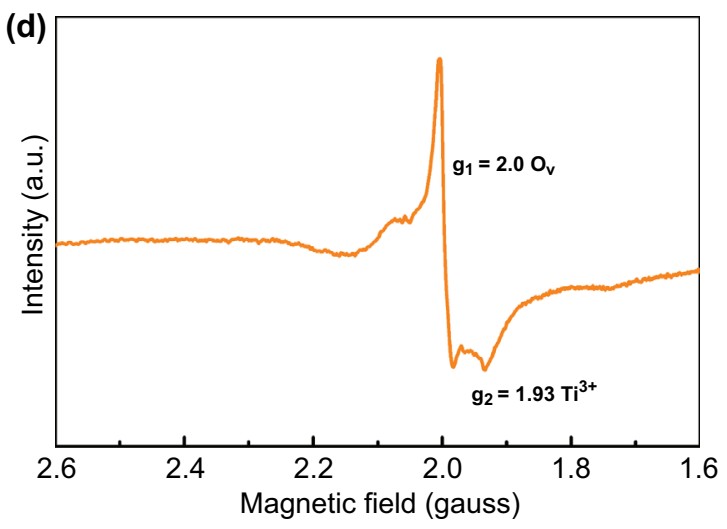

Fig. 3 Structure characterization of $\mathrm{M}-\mathrm{TiO}_{2} @ \mathrm{rGO}$ composite. a XRD of $\mathrm{M}-\mathrm{TiO}_{2}$ and $\mathrm{M}-\mathrm{TiO}_{2} @ \mathrm{rGO}$; b Raman of $\mathrm{M}-\mathrm{TiO} \mathrm{O}_{2}$, GO, and $\mathrm{M}-\mathrm{TiO} \mathrm{O}_{2} @$ rGO; $\mathbf{c}$ XPS curve of Ti $2 p$; and $\mathbf{d}$ EPR curve of $\mathrm{M}-\mathrm{TiO}_{2} @ \mathrm{rGO}$ 
(EPR) detection, a method to directly reveal oxygen vacancies, further confirmed the defect state (Fig. 3d). The strong signal at $g=2.0$ confirmed the existence of abundant oxygen vacancies and $g=1.93$ represented $\mathrm{Ti}^{3+}$ due to charge compensation during defective $\mathrm{M}-\mathrm{TiO}_{2}$ formation [21, 37, 40]. These above results strongly revealed that the massive lattice defects were mainly caused by the presence of a large number of oxygen vacancies and F doping, which could be attributed to the advantages of using the MXene parent phase. Furthermore, $\mathrm{M}-\mathrm{TiO}_{2} @ \mathrm{rGO}$ presented a specific surface area of $174 \mathrm{~m}^{2} \mathrm{~g}^{-1}$ with an abundance of micropores and mesopores, shown by the nitrogen adsorption-desorption isotherms (Fig. S16). Such a hierarchical porous structure was very beneficial for electrolyte soaking, resulting in large contact areas between the electrode and electrolyte.

\subsection{Electrochemical Performance and Kinetics Analysis of $\mathrm{M}-\mathrm{TiO}_{2} @$ rGO Electrode}

M-TiO ${ }_{2} @ \mathrm{rGO}$ foam could be applied directly as a selfsupporting electrode. In sodium ion half cells, a remarkable rate performance was observed with average discharge specific capacities of 308, 223, 193, 171, 150, and 142 $\mathrm{mAh} \mathrm{g}^{-1}$ at current densities of 50, 100, 200, 500, 1000, and $2000 \mathrm{~mA} \mathrm{~g}^{-1}$, respectively (Fig. 4a). The average voltage of the $\mathrm{M}-\mathrm{TiO}_{2} @ \mathrm{rGO}$ electrode was $0.7 \mathrm{~V}$ (Fig. 4b), which effectively avoided dendrite generation. The sloping discharge profiles demonstrated a possible pseudocapacitive behavior [15]. In addition, a common irreversible capacity was observed in the first discharge and cyclic voltammetry (CV) curves (Fig. S17a, b), with a Coulombic efficiency of $28 \%$. The irreversible capacity was related to some irreversible transformation between $\mathrm{Ti}^{3+}$ and $\mathrm{Ti}^{4+}$, irreversible insertion of sodium into porous structure, irreversible decomposition of the electrolyte, and the formation of solid electrolyte interphase (SEI) [15, 47, 48]. The ex-situ

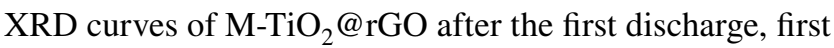
charge, and 1000 cycles showed that the peaks of $\mathrm{M}-\mathrm{TiO}_{2} @$ rGO were preserved, which demonstrated that the original structure remained unchanged during the sodiation or desodiation process (Fig. 4c). Even after 1000 cycles, the main peaks remained, suggesting favorable structural stability after repeated sodium ion insertion and desertion. Interestingly and typically, the $\mathrm{M}-\mathrm{TiO}_{2} @ \mathrm{rGO}$ electrode presented an electrochemical activation process during the initial cycles (Fig. 4d), in which the 2 nd, 3rd, 5th, and 10th cycles represented after $2,3,5$, and 10 cycles of galvanostatic charge-discharge testing (current density of $50 \mathrm{~mA} \mathrm{~g}^{-1}$ ), respectively. With cycling, a couple of anode/cathode peaks gradually appeared and became stable. Even after 1000 cycles, the anode/cathode peaks still remained well, suggesting a highly reversible sodium ion storage process. Such phenomena might have been caused by the transition of sodium ion storage from the surface to the bulk phase. This also suggested that $\mathrm{M}-\mathrm{TiO}_{2} @ \mathrm{rGO}$ presented multiple sodium ion storage mechanisms.

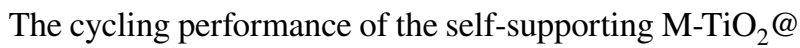
rGO electrode presented capacity retention of $97.2 \%$ after 1000 cycles at $1.0 \mathrm{~A} \mathrm{~g}^{-1}$ (Fig. 4e). Moreover, it demonstrated a capacity of $123.3 \mathrm{mAh} \mathrm{g}^{-1}$ with a capacity retention of $90.7 \%$ after 5000 cycles at $5.0 \mathrm{~A} \mathrm{~g}^{-1}$, corresponding to a decay of $0.018 \%$ per cycle, which was better than previous reports regarding sodium-based self-supporting anodes [8, 49-51]. From SEM images after 1000 cycles, $\mathrm{M}-\mathrm{TiO}_{2}$ nanoparticles did not show shedding or agglomeration but only smooth edges, demonstrating good stability (Fig. S18). Electrochemical impedance spectroscopy (EIS) presented a reduced electrochemical reaction resistance and more pseudocapacitance diffusion behaviors after 1000 cycles (Fig. S19), which were attributed to activation process during the cycling. In addition, it was noticed that the capacity contribution from rGO was negligible (Fig. S20) and pure $\mathrm{M}-\mathrm{TiO}_{2}$ exhibited a poor electrochemical performance due to severe agglomeration phenomenon (Fig. S21). Thus, the observed superior electrochemical performance of $\mathrm{M}-\mathrm{TiO}_{2} @ \mathrm{rGO}$ was attributed to the synergistic effects of rGO and defectrich $\mathrm{M}-\mathrm{TiO}_{2}$. The former provided a stable framework and enhanced electronic conductivity, while the later enhanced electrolyte soaking and provided many reaction active sites.

To reveal the $\mathrm{Na}$ ion storage mechanism, a series of kinetic analyses for $\mathrm{M}-\mathrm{TiO}_{2} @ \mathrm{rGO}$ electrodes were performed as shown in Fig. 5. Figure 5a shows the CV curves from 0.2 to $100 \mathrm{mV} \mathrm{s}^{-1}$. The electrochemical kinetics of $\mathrm{Na}$ ion storage was analyzed through the relation of the peak current $(i)$ and scan rate $(v)$ :

$i=a v^{b}$

In Eq. (3), the $b$-value is between 0.5 and 1 , in which the two ends represent the diffusion-controlled process and the capacitance-controlled process, respectively [15]. The $b$-value evaluated as the logarithm of Eq. (3) showed that 

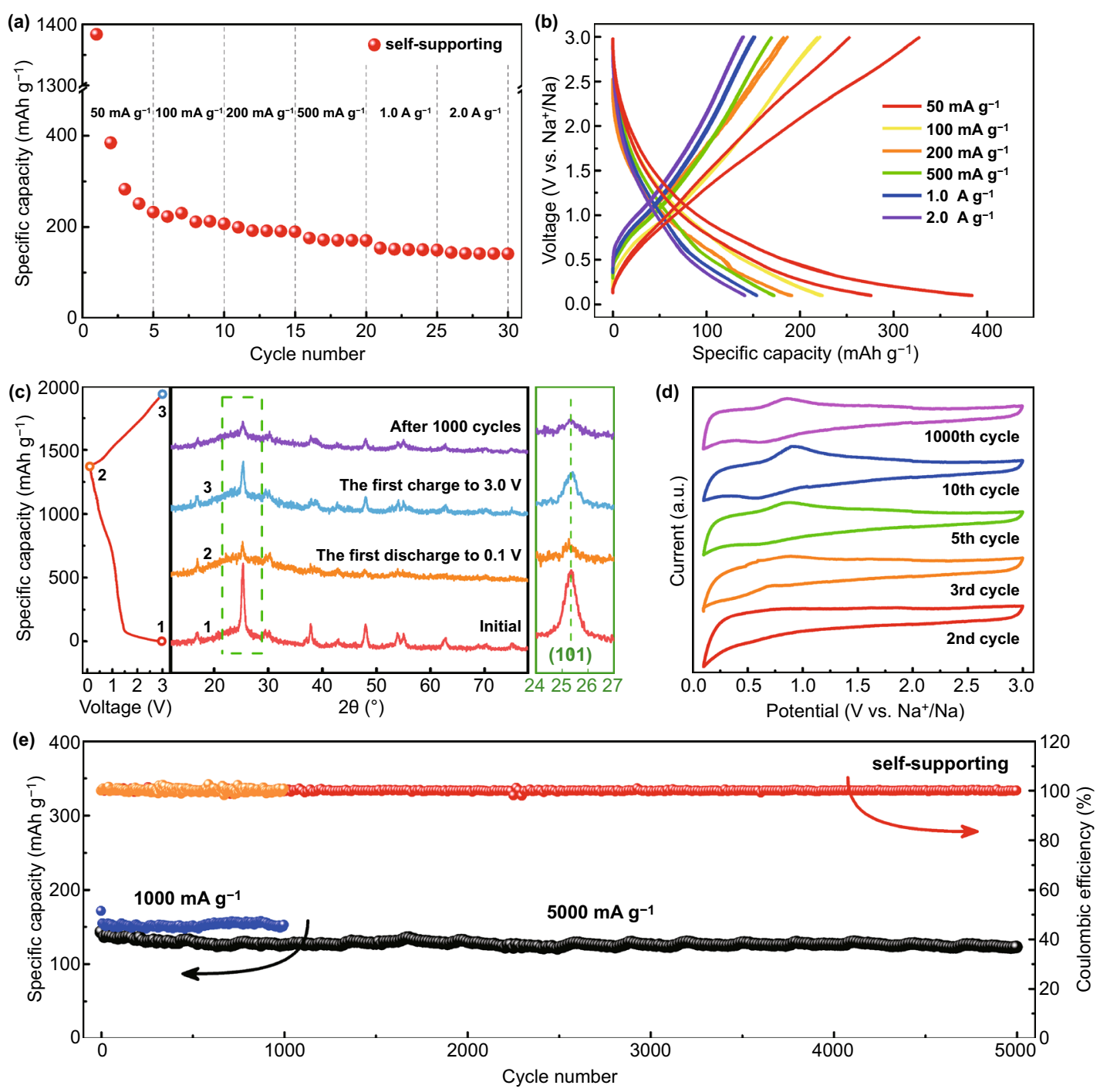

Fig. 4 Electrochemical characterization of the self-supporting $\mathrm{M}-\mathrm{TiO}_{2} @ \mathrm{rGO}$ electrode in half cells. a Rate performance; b charge-discharge curves between 0.1 and $3.0 \mathrm{~V}$ from $50 \mathrm{~mA} \mathrm{~g}^{-1}$ to $2.0 \mathrm{~A} \mathrm{~g}^{-1}$; $\mathbf{c}$ XRD curves at different charging and discharging stages; $\mathbf{d} \mathrm{CV}$ curves after galvanostatic charging-discharging tests with different cycles; and $\mathbf{e} 1000$ and 5000 cycles cycling performance at 1.0 and $5.0 \mathrm{Ag} \mathrm{g}^{-1}$

the $b$ of anode peaks was 0.94 and the $b$ of the cathode was 0.93 , at sweep rates range from 0.2 to $5.0 \mathrm{mV} \mathrm{s}^{-1}$ (Fig. $5 \mathrm{~b}$ ). This indicated that a capacitive process dominated the $\mathrm{Na}$ ion storage, leading to fast kinetics during charging and discharging. When the sweep rate was $>5.0 \mathrm{mV} \mathrm{s}^{-1}$, the $b$ of the anode decreased to 0.65 , implying that the diffusion process was the restrictive step [52]. The charge $(Q)$ versus $v^{-1 / 2}$ plot more intuitively illustrated the results (Fig. 5b, inset). When the sweep rate was $<5.0 \mathrm{mV} \mathrm{s}^{-1}$, the total charge did not change considerably with increased scan rates, which was because the capacitor behavior was less affected by the change of sweep speed. However, when the sweep rate was

3



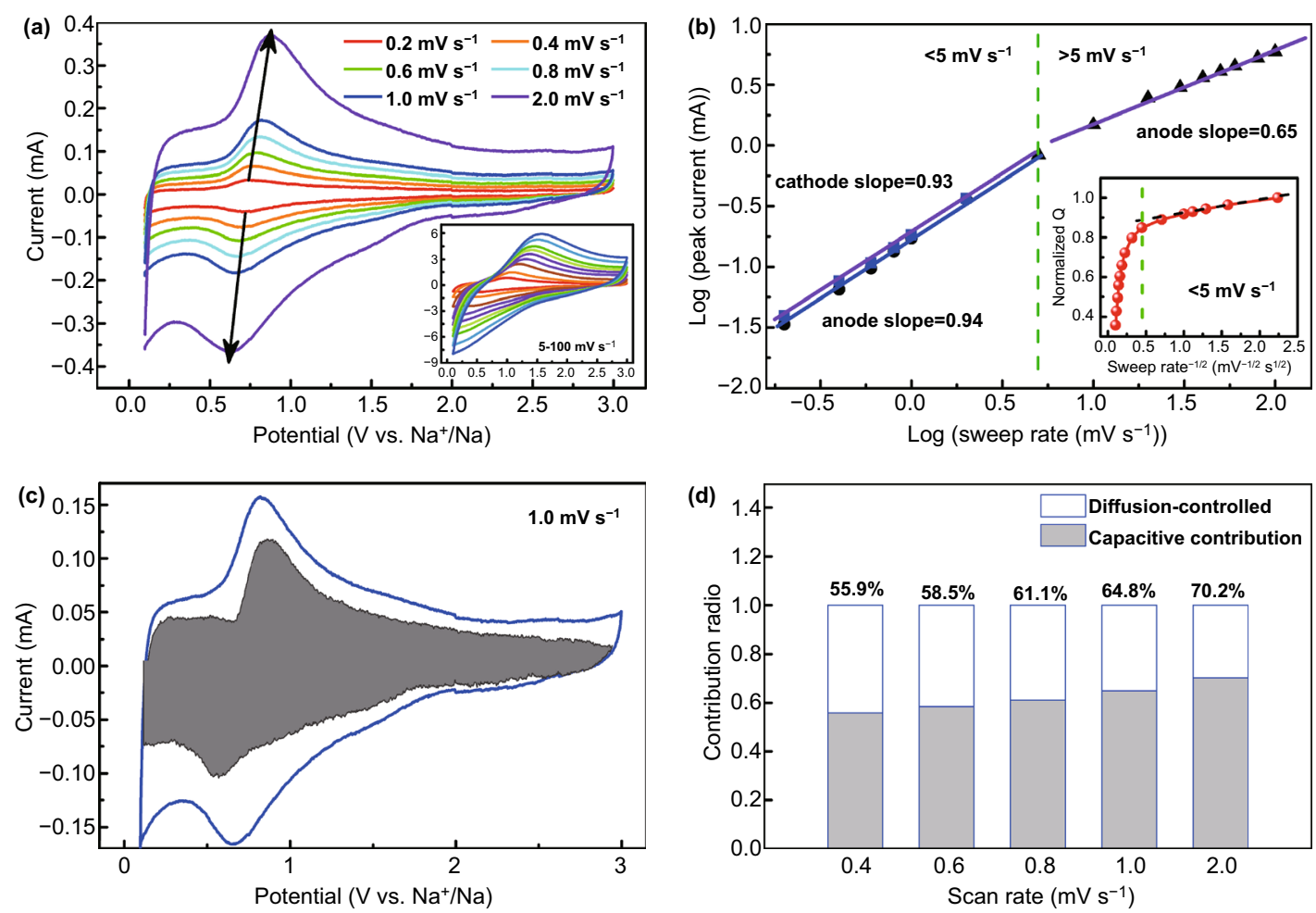

Fig. 5 Kinetics analysis of sodium ion storage behavior in the $\mathrm{M}-\mathrm{TiO}_{2} @ \mathrm{rGO}$ electrode. a $\mathrm{CV}$ curves at different scan rates, inset: from 5 to $100 \mathrm{mV} \mathrm{s}^{-1} ; \mathbf{b} b$-value analysis through the relation of the peak current $(i)$ and the scan rate $(v)$; inset: normalized charge versus scan rate ${ }^{-1 / 2} ; \mathbf{c}$ capacitive contribution area (gray) at the $1.0 \mathrm{mV} \mathrm{s}^{-1}$; and $\mathbf{d}$ capacitive contribution ratios at $0.4-2 \mathrm{mV} \mathrm{s}-1$

specific algorithms can be seen in the Supporting Information and the results showed in Figs. S22 and 5c, d. The $\mathrm{CV}$ area (gray) of capacitive contribution at $1.0 \mathrm{mV} \mathrm{s}^{-1}$ was displayed in Fig. 5c. The ratios of capacitive capacity showed a gradually increasing phenomenon as scan rates and a large capacitance contribution of $70.2 \%$ was obtained at $2.0 \mathrm{mV} \mathrm{s}^{-1}$ (Fig. 5d). Based on the above results, the observed capable rate and stable cycling performance could be ascribed to the improved electron conductivity and ions diffusion as well as a large pseudocapacitance contribution, arising from the in nanoscale and defect engineering.

\subsection{Sodium Ion Battery and Capacitor Based on $\mathrm{M}-\mathrm{TiO}_{2} @$ rGO Universal Anode}

The $\mathrm{M}-\mathrm{TiO}_{2} @ \mathrm{rGO}$ foam electrode presented a lower working voltage, remarkable rate ability, and excellent cycling stability, demonstrating potential application as a universal anode for both SIBs and SICs. Thus, $\mathrm{M}-\mathrm{TiO}_{2} @ \mathrm{rGO} / /$
$\mathrm{Na}_{3} \mathrm{~V}_{2}\left(\mathrm{PO}_{4}\right)_{3}$ SIBs and $\mathrm{M}-\mathrm{TiO}_{2} @ \mathrm{rGO} / /$ biomass-derived active carbon SICs were designed and assembled.

A SIB with $\mathrm{Na}_{3} \mathrm{~V}_{2}\left(\mathrm{PO}_{4}\right)_{3}(\mathrm{NVP})$ as the cathode and activated $\mathrm{M}-\mathrm{TiO}_{2} @ \mathrm{rGO}$ as the anode was assembled. Before that, the electrochemical performance of NVP was investigated in a $\mathrm{Na}$ ion half-cell at the voltage window of 2.0-4.3 V. The charge/discharge profiles at different current densities were shown in Fig. S23a, with a charging platform of $3.4 \mathrm{~V}$ and a discharging platform of $3.3 \mathrm{~V}$ at $50 \mathrm{~mA} \mathrm{~g}^{-1}$. A stable cycling performance with capacity retention of $85 \%$ was obtained after 200 cycles at $500 \mathrm{~mA} \mathrm{~g}^{-1}$ (Fig. S23b). To better match the qualities of anode and cathode to ensure electrochemical performance, $\mathrm{M}-\mathrm{TiO}_{2} @ \mathrm{rGO}$ was coated onto copper foil to flexibly regulate the mass loads of active materials. The rate performance of the coating- $\mathrm{M}-\mathrm{TiO}_{2} @$ rGO electrode showed higher specific capacities than self-

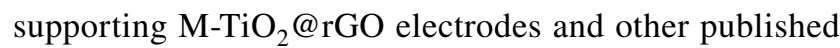
reports at the same conditions (Fig. S24a). Furthermore, this half-cell exhibited an amazing cycling performance. At an 
ultra-high current density of $10 \mathrm{~A} \mathrm{~g}^{-1}$, a capacity of 127.2 $\mathrm{mAh} \mathrm{g}^{-1}$ and capacity retention of $84.6 \%$ were still obtained after 10,000 cycles (Fig. S24b).

The electrochemical performance of SIBs was optimized by setting the electrode mass ratio at 1:3 (anode: cathode). The galvanostatic charge-discharge test was operated at

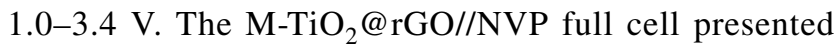
average capacities of 247.4, 200.3, 178.3, 148.3, and 135.8 $\mathrm{mAh} \mathrm{g}^{-1}$ at current densities of 50, 200, 500, 1000, and $2000 \mathrm{~mA} \mathrm{~g}^{-1}$, respectively, demonstrating a good rate performance (Fig. 6a). With current density increased, the shapes of the charge/discharge profiles retained well (Fig. 6b). In addition, the cycle stability was tested at the current density of $500 \mathrm{~mA} \mathrm{~g}^{-1}$ (Fig. 6c). The $\mathrm{TiO}_{2} @ \mathrm{rGO} / / \mathrm{NVP}$ full cell exhibited a discharge capacity of $177.1 \mathrm{mAh} \mathrm{g}^{-1}$ in the first cycle and capacity retention of $74 \%\left(130.7 \mathrm{mAh} \mathrm{g}^{-1}\right)$ after 200 cycles. Meanwhile, the Coulomb efficiency tended to $100 \%$, indicating a perfect kinetics match between the cathode and anode. It should be noted that the decreased capacity of the full cell was mainly caused by the cathode, based on the results of half cells. Thus, if $\mathrm{M}-\mathrm{TiO}_{2} @ \mathrm{rGO}$ was matched with other more stable cathodes, the electrochemical performance would be further improved.

To achieve Na-based energy storage devices with higher power density, a SIC was assembled with activated $\mathrm{M}-\mathrm{TiO}_{2} @ \mathrm{rGO}$ as the anode and a 3D hierarchical porous activated carbon (HPAC) derived from coir [35] as the cathode. The electrochemical performance of the HPAC in Na-ion half-cell was measured at 3.0-4.2 V, with outstanding rate and cycling performances (Fig. S25). A typical electric double layer capacitor (EDLC) behavior of HPAC was demonstrated in the rectangular $\mathrm{CV}$ curves and triangular chronopotential potential (CP) curves (Fig. S25a, c). To better match the quality between the positive and negative electrodes to ensure electrochemical performance, the coating- $\mathrm{M}-\mathrm{TiO}_{2} @ \mathrm{rGO}$ electrode was used as the anode. The schematic of the SIC is shown in Fig. 7a. In the charging stage, $\mathrm{Na}^{+}$intercalated into the $\mathrm{M}-\mathrm{TiO}_{2} @ \mathrm{rGO}$ anode from the electrolyte, while $\mathrm{ClO}_{4}{ }^{-}$anions absorbed on the HPAC cathode to balance the charge in electrolyte [53]. During the discharge stage, a reverse reaction occurred. To obtain higher energy density and cycling stability, the working
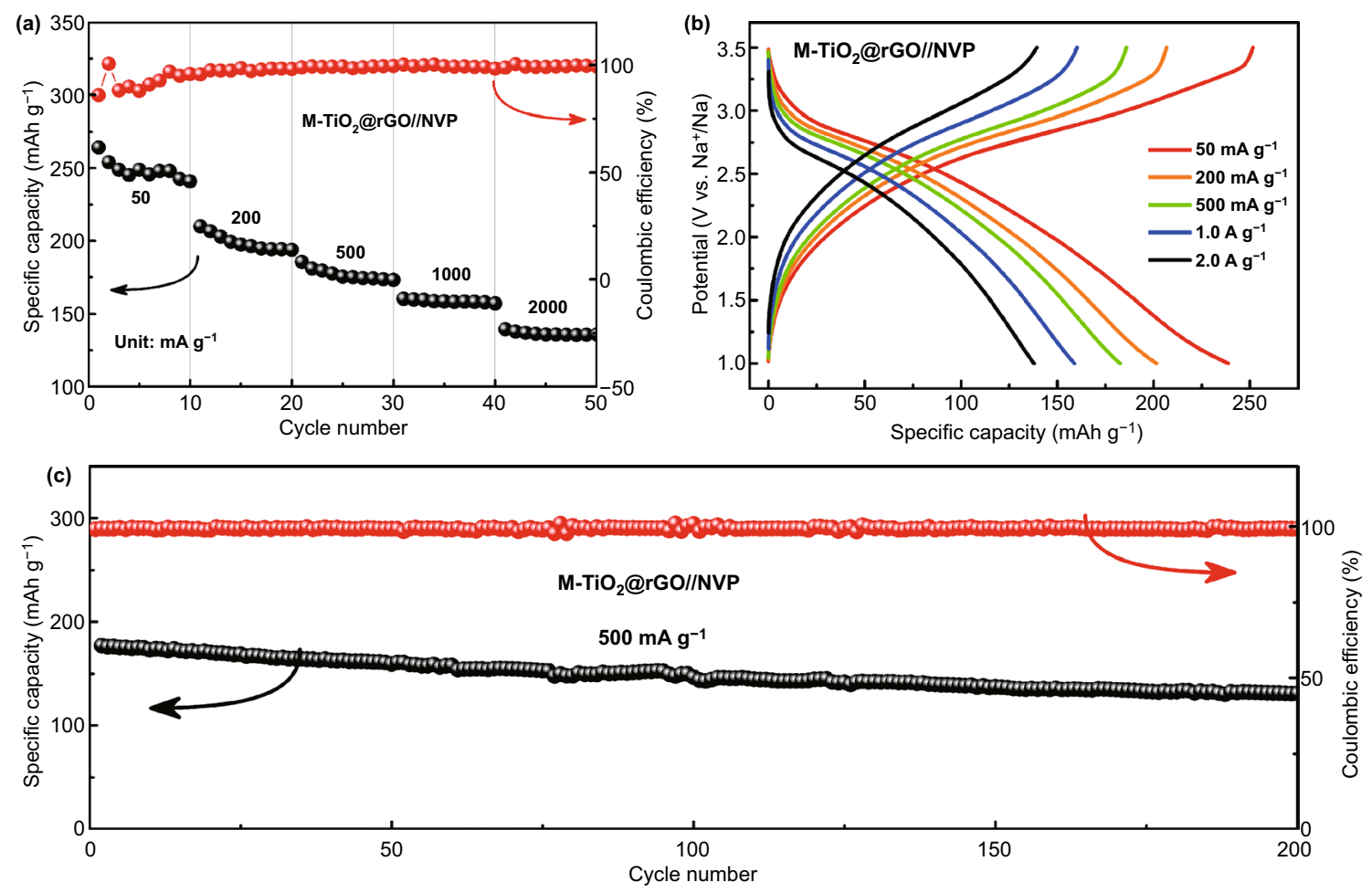

Fig. 6 Electrochemical performance of the sodium ion batteries ( $\mathrm{SIBs}$ ) with the NVP as cathodes and coated $\mathrm{M}-\mathrm{TiO}_{2} @ \mathrm{rGO}$ as anodes. a Rate performance; $\mathbf{b}$ charge-discharge curves at different current densities; and $\mathbf{c}$ cycling performance at $500 \mathrm{~mA} \bullet \mathrm{g}^{-1}$ 

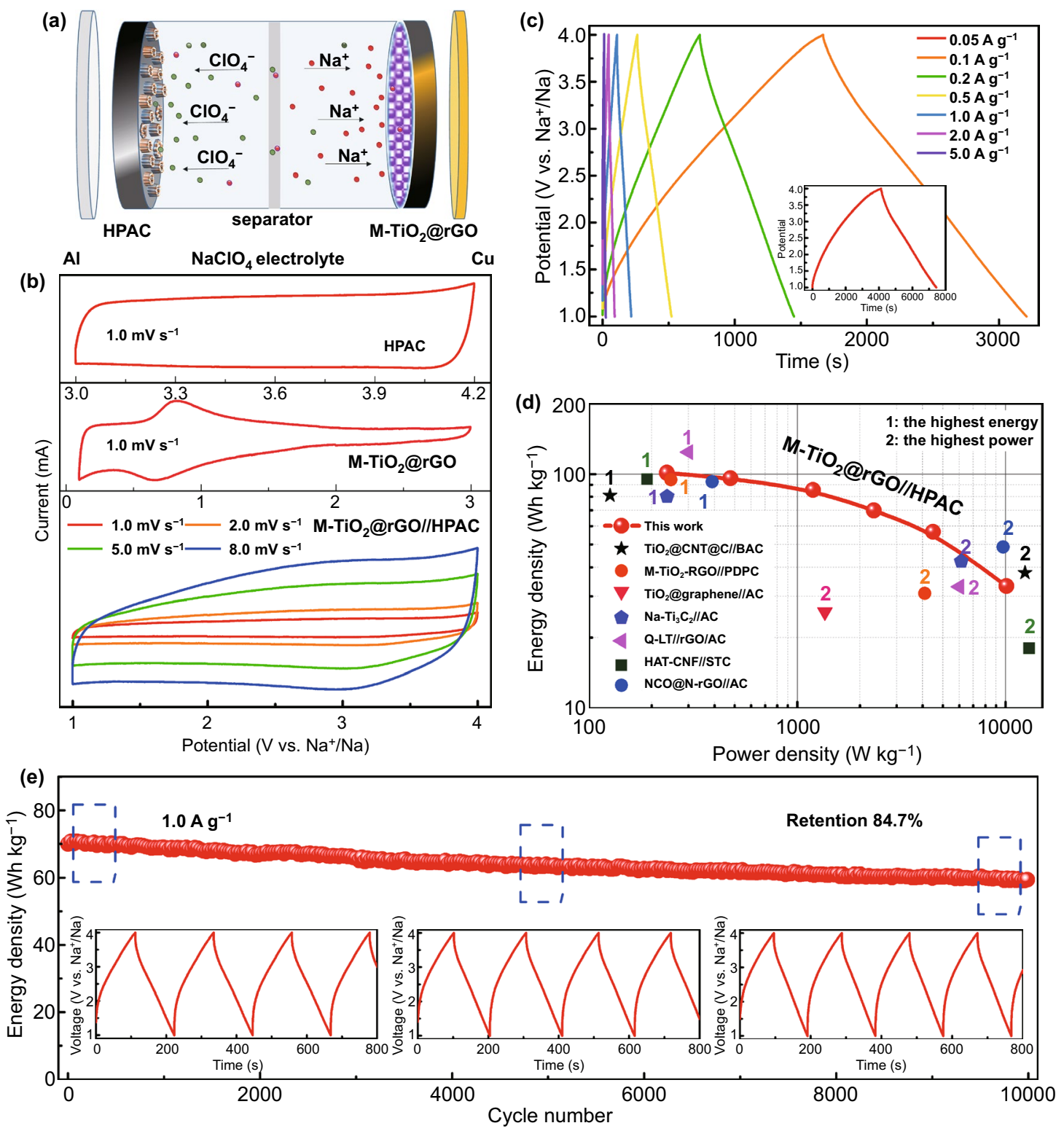

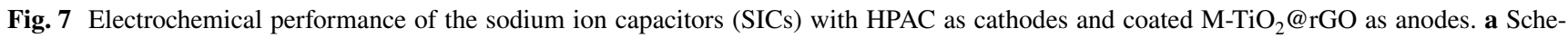
matic of the SICs; $\mathbf{b}$ CV curves of HPAC, M-TiO $@$ rGO, and M-TiO $@$ @ rGO//HPAC; $\mathbf{c}$ CP curves at different current densities; $\mathbf{d}$ Ragone plot of power density and energy density; and e cycling performance at $1.0 \mathrm{~A} \mathrm{~g}^{-1}$, inset: $\mathrm{CP}$ curves at different states

voltage range of the SIC was selected to be 1.0-4.0 V [23]. The optimal mass ratio was investigated via rate and cycling performance tests (Fig. S26), which was set at 1:1.0, 1:1.5, 1:2.0, and 1:3.0 for anode/cathode. The device with a mass ratio of 1:1.5 displayed higher energy density and the best cycling performance, with capacity retention of $88.6 \%$ after 1000 cycles $\left(2.0 \mathrm{~A} \mathrm{~g}^{-1}\right)$.

The optimized SICs with a mass ratio of 1:1.5 and an operating voltage window of $1.0-4.0 \mathrm{~V}$ were chosen to further estimate the electrochemical performance (Fig. 7). The CV curves before and after assembly are shown in Fig. 7b, and the CV curves of SIC displayed an approximate rectangle with a slight peak attributed to certain pseudocapacitance reactions at high voltage, which was beneficial for achieving high energy density. Based on galvanostatic charge-discharge measurements, the typical near-linear $\mathrm{CP}$ curves at $1.0-4.0 \mathrm{~V}$ indicated a near ideal capacitive property, which implied rapid ion storage kinetics (Fig. 7c) 
[56]. The energy and power densities were calculated based on the total masses of the anode and cathode. A superhigh energy density of $124.3 \mathrm{Wh} \mathrm{kg}^{-1}$ was obtained in the first cycle. After 5 cycles activation process at $0.05 \mathrm{~A} \mathrm{~g}^{-1}$, a high energy density of $101.2 \mathrm{Wh} \mathrm{kg}^{-1}$ was achieved at a power density of $236.0 \mathrm{~W} \mathrm{~kg}^{-1}\left(0.1 \mathrm{~A} \mathrm{~g}^{-1}\right)$ and an ultrahigh power density of $10,103.7 \mathrm{~W} \mathrm{~kg}^{-1}$ was obtained at an energy density of $33.2 \mathrm{Wh} \mathrm{kg}^{-1}\left(5.0 \mathrm{~A} \mathrm{~g}^{-1}\right)$. Such a remarkable electrochemical performance was at the top level compared to previous SICs reports (Fig. 7d), such as $\mathrm{TiO}_{2} @ \mathrm{CNT} @ \mathrm{C} / /$

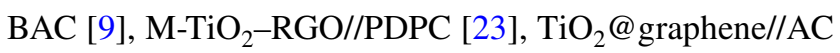
[7], HAT-CNF//STC [54], Na-Ti ${ }_{3} \mathrm{C}_{2} / / \mathrm{AC}$ [55], NCO@N$\mathrm{rGO} / / \mathrm{AC}$ [47], and Q-LT//rGO/AC [53]. Moreover, these SICs presented a long-term stable cycling performance with an energy retention ratio of $84.7 \%$ after 10,000 cycles at $1.0 \mathrm{~A} \mathrm{~g}^{-1}$ (Fig. 7e). In addition, no deformation occurred in the charge/discharge profiles, which further illustrated an excellent reversibility and perfect dynamics match between the anode and cathode. The above results suggest favorable designs are found here for the anode and cathode of Naion capacitors, which will provide a feasible strategy for the practical application of sodium ion energy storage devices.

\section{Conclusions}

In summary, $\mathrm{Ti}_{2} \mathrm{CT}_{x}$-derived defective $\mathrm{TiO}_{2}$ nanoparticles were synthesized via a facile and environmentally friendly approach, $\mathrm{Ti}_{2} \mathrm{CT}_{x}$ MXene aqueous phase splitting, in which the $\mathrm{TiO}_{2}$ formation mechanism of $\mathrm{Ti}_{2} \mathrm{CT}_{x}$ binding to $\mathrm{OH}^{-}$produced by water decomposition was first revealed. Employing MXene parent phase achieved rich oxygen vacancies and F-doped metal oxides nanoparticles in situ, which fundamentally improved electrons/ions conductivity. Furthermore, an $\mathrm{M}-\mathrm{TiO}_{2} @ \mathrm{rGO}$ foam was synthesized and exhibited a hierarchical porous structure, which benefitted electrolyte permeation and enhanced ion transport. Employed as a free-standing anode for Na ion half cells, this material showed excellent rate performance and ultra-long cycling stability, with a retention ratio of $90.7 \%$ even after 5000 cycles at $5.0 \mathrm{~A} \mathrm{~g}^{-1}$. Electrochemical analysis demonstrated pseudocapacitance-dominated hybrid sodium storage mechanism. At $2.0 \mathrm{mV} \mathrm{s}^{-1}$, capacitive contribution is $\sim 70 \%$, which was caused by the defects and nano-size particles. Finally, the distinctive $\mathrm{M}-\mathrm{TiO}_{2} @ \mathrm{rGO}$ electrode displayed a suitable electrochemical performance as a universal anode for both $\mathrm{M}-\mathrm{TiO}_{2} @ \mathrm{rGO} / / \mathrm{NVP}$ SIBs and $\mathrm{M}-\mathrm{TiO}_{2} @ \mathrm{rGO} / /$ HPAC SICs. The SICs showed a high energy density of 101.2 $\mathrm{Wh} \mathrm{kg}^{-1}$ at a power density of $236.0 \mathrm{~W} \mathrm{~kg}^{-1}$ and an ultrahigh power density of $10,103.7 \mathrm{~W} \mathrm{~kg}^{-1}$ at a mezzo energy density of $33.2 \mathrm{Wh} \mathrm{kg}^{-1}$, along with outstanding cyclic stability with energy retention ratio of $84.7 \%$ after 10,000 cycles at $1.0 \mathrm{~A} \mathrm{~g}^{-1}$. This study will facilitate the rapid development of anodes for high-performance sodiumbased energy storage devices and inspire more applications for MXene.

Acknowledgements This work was supported by the National Natural Science Foundation of China (51702063, 51672056), Natural Science Foundation of Heilongjiang (LC2018004), China Postdoctoral Science Foundation (2018M630340, 2019T120254) and the Fundamental Research Funds for the Central University.

Open Access This article is licensed under a Creative Commons Attribution 4.0 International License, which permits use, sharing, adaptation, distribution and reproduction in any medium or format, as long as you give appropriate credit to the original author(s) and the source, provide a link to the Creative Commons licence, and indicate if changes were made. The images or other third party material in this article are included in the article's Creative Commons licence, unless indicated otherwise in a credit line to the material. If material is not included in the article's Creative Commons licence and your intended use is not permitted by statutory regulation or exceeds the permitted use, you will need to obtain permission directly from the copyright holder. To view a copy of this licence, visit http://creativecommons.org/licenses/by/4.0/.

Electronic supplementary material The online version of this article (https://doi.org/10.1007/s40820-020-00471-9) contains supplementary material, which is available to authorized users.

\section{References}

1. B. Dunn, H. Kamath, J.-M. Tarascon, Electrical energy storage for the grid: a battery of choices. Science 334(6058), 928-935 (2011). https://doi.org/10.1126/science.1212741

2. M. Park, J. Ryu, W. Wang, J. Cho, Material design and engineering of next-generation flow-battery technologies. Nat. Rev. Mater. 2(1), 16080 (2017). https://doi.org/10.1038/natre vmats.2016.80

3. C. Vaalma, D. Buchholz, M. Weil, S. Passerini, A cost and resource analysis of sodium-ion batteries. Nat. Rev. Mater. 3(4), 18013 (2018). https://doi.org/10.1038/natrevmats .2018 .13

4. S. Li, Z. Zhao, C. Li, Z. Liu, D. Li, SnS $2 @$ C hollow nanospheres with robust structural stability as high-performance 
anodes for sodium ion batteries. Nano-Micro Lett. 11(1), 14 (2019). https://doi.org/10.1007/s40820-019-0243-7

5. Y. Jiang, X. Zhou, D. Li, X. Cheng, F. Liu, Y. Yu, Highly reversible $\mathrm{Na}$ storage in $\mathrm{Na}_{3} \mathrm{~V}_{2}(\mathrm{PO} 4)_{3}$ by optimizing nanostructure and rational surface engineering. Adv. Energy Mater. 8(16), 1800068 (2018). https://doi.org/10.1002/aenm.20180 0068

6. J. Zhao, X. Yang, Y. Yao, Y. Gao, Y. Sui et al., Moving to aqueous binder: a valid approach to achieving high-rate capability and long-term durability for sodium-ion battery. Adv. Sci. 5(4), 1700768 (2018). https://doi.org/10.1002/advs.20170 0768

7. Z. Le, F. Liu, P. Nie, X. Li, X. Liu et al., Pseudocapacitive sodium storage in mesoporous single-crystal-like $\mathrm{TiO}_{2}$-graphene nanocomposite enables high-performance sodium-ion capacitors. ACS Nano 11(3), 2952-2960 (2017). https://doi. org/10.1021/acsnano.6b08332

8. Z. Xia, H. Sun, X. He, Z. Sun, C. Lu, In situ construction of $\mathrm{CoSe}_{2} @$ vertical-oriented graphene arrays as self-supporting electrodes for sodium-ion capacitors and electrocatalytic oxygen evolution. Nano Energy 60, 385-393 (2019). https ://doi.org/10.1016/j.nanoen.2019.03.052

9. Y.E. Zhu, L. Yang, J. Sheng, Y. Chen, H. Gu, J. Wei, Z. Zhou, Fast sodium storage in $\mathrm{TiO}_{2} @ \mathrm{CNT} @ \mathrm{C}$ nanorods for high-performance Na-ion capacitors. Adv. Energy Mater. 7(22), 1701222 (2017). https://doi.org/10.1002/aenm.20170 1222

10. Y. Sun, S. Guo, H. Zhou, Exploration of advanced electrode materials for rechargeable sodium-ion batteries. Adv. Energy Mater. 9, 1800212 (2018). https://doi.org/10.1002/aenm.20180 0212

11. F. Wu, C. Zhao, S. Chen, Y. Lu, Y. Hou, Y.S. Hu, J. Maier, Y. Yan, Multi-electron reaction materials for sodium-based batteries. Mater. Today 21(9), 960-973 (2018). https://doi. org/10.1016/j.mattod.2018.03.004

12. C. Peng, H. Chen, G. Zhong, W. Tang, Y. Xiang et al., Capacity fading induced by phase conversion hysteresis within alloying phosphorus anode. Nano Energy 58, 560-567 (2019). https ://doi.org/10.1016/j.nanoen.2019.01.035

13. P. Bai, Y. He, P. Xiong, X. Zhao, K. Xu, Y. Xu, Long cycle life and high rate sodium-ion chemistry for hard carbon anodes. Energy Storage Mater. 13, 274-282 (2018). https:// doi.org/10.1016/j.ensm.2018.02.002

14. S. Guo, Q. Li, P. Liu, M. Chen, H. Zhou, Environmentally stable interface of layered oxide cathodes for sodium-ion batteries. Nat. Commun. 8(1), 135 (2017). https://doi.org/10.1038/ s41467-017-00157-8

15. Y. Fang, R. Hu, B. Liu, Y. Zhang, K. Zhu et al., Mxene-derived $\mathrm{TiO}_{2} /$ reduced graphene oxide composite with an enhanced capacitive capacity for Li-ion and K-ion batteries. J. Mater. Chem. A 7(10), 5363-5372 (2019). https://doi.org/10.1039/ C8TA12069B

16. L. Sang, L. Lei, C. Burda, Electrochemical fabrication of rGOembedded $\mathrm{Ag}-\mathrm{TiO}_{2}$ nanoring/nanotube arrays for plasmonic solar water splitting. Nano-Micro Lett. 11(1), 97 (2019). https ://doi.org/10.1007/s40820-019-0329-2
17. Q. Gan, H. He, Y. Zhu, Z. Wang, N. Qin, S. Gu, Z. Li, W. Luo, Z. Lu, Defect-assisted selective surface phosphorus doping to enhance rate capability of titanium dioxide for sodium ion batteries. ACS Nano 13(8), 9247-9258 (2019). https://doi. org/10.1021/acsnano.9b03766

18. C. Li, T. Wang, Z.J. Zhao, W. Yang, J.F. Li et al., Promoted fixation of molecular nitrogen with surface oxygen vacancies on plasmon-enhanced $\mathrm{TiO}_{2}$ photoelectrodes. Angew. Chem. Int. Ed. 57(19), 5278-5282 (2018). https://doi.org/10.1002/ anie. 201713229

19. Y. Zhang, Z. Ding, C.W. Foster, C.E. Banks, X. Qiu, X. Ji, Oxygen vacancies evoked blue $\mathrm{TiO}_{2}$ (B) nanobelts with efficiency enhancement in sodium storage behaviors. Adv. Funct. Mater. 27(27), 1700856 (2017). https://doi.org/10.1002/ adfm.201700856

20. L. Huang, X. Zhou, R. Xue, P. Xu, S. Wang et al., Low-temperature growing anatase $\mathrm{TiO}_{2} / \mathrm{SnO}_{2}$ multi-dimensional heterojunctions at MXene conductive network for high-efficient perovskite solar cells. Nano-Micro Lett. 12(1), 44 (2020). https ://doi.org/10.1007/s40820-020-0379-5

21. W. Zhang, L. Cai, S. Cao, L. Qiao, Y. Zeng et al., Electrode materials: interfacial lattice-strain-driven generation of oxygen vacancies in an aerobic-annealed $\mathrm{TiO}_{2}$ (B) electrode. Adv. Mater. 31(52), 1970367 (2019). https://doi.org/10.1002/ adma.201970367

22. B. Li, B. Xi, Z. Feng, Y. Lin, J. Liu, J. Feng, Y. Qian, S. Xiong, Hierarchical porous nanosheets constructed by graphene-coated, interconnected $\mathrm{TiO}_{2}$ nanoparticles for ultrafast sodium storage. Adv. Mater. 30(10), 1705788 (2018). https:// doi.org/10.1002/adma.201705788

23. R. Wang, S. Wang, Y. Zhang, D. Jin, X. Tao, L. Zhang, Graphene-coupled $\mathrm{Ti}_{3} \mathrm{C}_{2}$ MXenes-derived $\mathrm{TiO}_{2}$ mesostructure: promising sodium-ion capacitor anode with fast ion storage and long-term cycling. J. Mater. Chem. A 6(3), 1017-1027 (2018). https://doi.org/10.1039/C7TA09153B

24. X. Zhang, J. Li, J. Li, L. Han, T. Lu, X. Zhang, G. Zhu, L. Pan, 3D $\mathrm{TiO}_{2} @$ nitrogen-doped carbon/ $\mathrm{Fe}_{7} \mathrm{~S}_{8}$ composite derived from polypyrrole-encapsulated alkalized MXene as anode material for high-performance lithium-ion batteries. Chem. Eng. J. 385, 123394 (2020). https://doi.org/10.1016/j. cej.2019.123394

25. P. Nakhanivej, X. Yu, S.K. Park, S. Kim, J.-Y. Hong et al., Revealing molecular-level surface redox sites of controllably oxidized black phosphorus nanosheets. Nat. Mater. 18(2), 156-162 (2019). https://doi.org/10.1038/s41563-018-0230-2

26. X. Yu, S. Yun, J.S. Yeon, P. Bhattacharya, L. Wang, S.W. Lee, X. Hu, H.S. Park, Emergent pseudocapacitance of 2D nanomaterials. Adv. Energy Mater. 8(13), 1702930 (2018). https://doi.org/10.1002/aenm.201702930

27. Y. Fang, Y. Zhang, K. Zhu, R. Lian, Y. Gao et al., Lithiophilic three-dimensional porous $\mathrm{Ti}_{3} \mathrm{C}_{2} \mathrm{~T}_{x}-\mathrm{rGO}$ membrane as a stable scaffold for safe alkali metal ( $\mathrm{Li}$ or $\mathrm{Na}$ ) anodes. ACS Nano 13(12), 14319-14328 (2019). https://doi.org/10.1021/acsna no. 9 b0 07729

28. H. He, Q. Gan, H. Wang, G.-L. Xu, X. Zhang et al., Structure-dependent performance of $\mathrm{TiO}_{2} / \mathrm{C}$ as anode material for 
Na-ion batteries. Nano Energy 44, 217-227 (2018). https:// doi.org/10.1016/j.nanoen.2017.11.077

29. Y. Xing, S. Wang, B. Fang, G. Song, D.P. Wilkinson, S. Zhang, N-doped hollow urchin-like anatase $\mathrm{TiO}_{2} @ \mathrm{C}$ composite as a novel anode for Li-ion batteries. J. Power Sources 385, 10-17 (2018). https://doi.org/10.1016/j.jpowsour.2018.02.077

30. Y. Zhu, L. Peng, Z. Fang, C. Yan, X. Zhang, G. Yu, Structural engineering of 2D nanomaterials for energy storage and catalysis. Adv. Mater. 30(15), 1706347 (2018). https://doi. org/10.1002/adma.201706347

31. A. Naldoni, M. Allieta, S. Santangelo, M. Marelli, F. Fabbri et al., Effect of nature and location of defects on bandgap narrowing in black $\mathrm{TiO}_{2}$ nanoparticles. J. Am. Chem. Soc. 134(18), 7600-7603 (2012). https://doi.org/10.1021/ja301 2676

32. Q. Wu, J.P. Zheng, M. Hendrickson, E.J. Plichta, Dry process for fabricating low cost and high performance electrode for energy storage devices. MRS Adv. 4(15), 857-863 (2019). https://doi.org/10.1557/adv.2019.29

33. S. Wang, Q. Wang, W. Zeng, M. Wang, L. Ruan, Y. Ma, A new free-standing aqueous zinc-ion capacitor based on $\mathrm{MnO}_{2}-\mathrm{CNT}$ cathode and MXene anode. Nano-Micro Lett. 11(1), 70 (2019). https://doi.org/10.1007/s4082 0-019-0301-1

34. Y. Zhu, S. Murali, W. Cai, X. Li, J.W. Suk, J.R. Potts, R.S. Ruoff, Graphene and graphene oxide: synthesis, properties, and applications. Adv. Mater. 22(35), 3906-3924 (2010). https://doi.org/10.1002/adma.201001068

35. L. Yin, Y. Chen, X. Zhao, B. Hou, B. Cao, 3-Dimensional hierarchical porous activated carbon derived from coconut fibers with high-rate performance for symmetric supercapacitors. Mater. Design 111, 44-50 (2016). https://doi. org/10.1016/j.matdes.2016.08.070

36. Z.W. Seh, K.D. Fredrickson, B. Anasori, J. Kibsgaard, A.L. Strickler et al., Two-dimensional molybdenum carbide (MXene) as an efficient electrocatalyst for hydrogen evolution. ACS Energy Lett. 1(3), 589-594 (2016). https://doi. org/10.1021/acsenergylett.6b00247

37. H. He, Q. Zhang, H. Wang, H. Zhang, J. Li, Z. Peng, Y. Tang, M. Shao, Defect-rich $\mathrm{TiO}_{2}-\delta$ nanocrystals confined in a mooncake-shaped porous carbon matrix as an advanced $\mathrm{Na}$ ion battery anode. J. Power Sources 354, 179-188 (2017). https://doi.org/10.1016/j.jpowsour.2017.04.035

38. H. Xu, X. Yin, X. Li, M. Li, S. Liang, L. Zhang, L. Cheng, Lightweight $\mathrm{Ti}_{2} \mathrm{CT}_{\mathrm{x}}$ MXene/poly (vinyl alcohol) composite foams for electromagnetic wave shielding with absorption dominated feature. ACS Appl. Mater. Interfaces 11, 1019810207 (2019). https://doi.org/10.1021/acsami.8b21671

39. Y. Zhao, Y. Zhao, R. Shi, B. Wang, G.I. Waterhouse, L.Z. $\mathrm{Wu}$, C.H. Tung, T. Zhang, Tuning oxygen vacancies in ultrathin $\mathrm{TiO}_{2}$ nanosheets to boost photocatalytic nitrogen fixation up to $700 \mathrm{~nm}$. Adv. Mater. 31(16), 1806482 (2019). https://doi.org/10.1002/adma.201806482

40. Y. Yang, K. Ye, D. Cao, P. Gao, M. Qiu, L. Liu, P. Yang, Efficient charge separation from F-selective etching and doping of anatase- $\mathrm{TiO}_{2}\{001\}$ for enhanced photocatalytic hydrogen production. ACS Appl. Mater. Interfaces 10(23), 19633-19638 (2018). https://doi.org/10.1021/acsami.8b028 04

41. L. Hüttenhofer, F. Eckmann, A. Lauri, J. Cambiasso, E. Pensa et al., Anapole excitations in oxygen vacancy-rich $\mathrm{TiO}_{2-x}$ nanoresonators: tuning the absorption for photocatalysis in the visible. ACS Nano 14, 2456-2464 (2020). https ://doi.org/10.1021/acsnano.9b09987

42. H. Ren, R. Yu, J. Qi, L. Zhang, Q. Jin, D. Wang, Hollow multishelled heterostructured anatase $/ \mathrm{TiO}_{2}(\mathrm{~B})$ with superior rate capability and cycling performance. Adv. Mater. 31(10), 1805754 (2019). https://doi.org/10.1002/adma.201805754

43. N.A. Kumar, R.R. Gaddam, S.R. Varanasi, D. Yang, S.K. Bhatia, X. Zhao, Sodium ion storage in reduced graphene oxide. Electrochim. Acta 214, 319-325 (2016). https://doi. org/10.1016/j.electacta.2016.08.058

44. B. Ahmed, D.H. Anjum, M.N. Hedhili, Y. Gogotsi, H.N. Alshareef, $\mathrm{H}_{2} \mathrm{O}_{2}$ assisted room temperature oxidation of $\mathrm{Ti}_{2} \mathrm{C}$ MXene for Li-ion battery anodes. Nanoscale 8(14), 7580-7587 (2016). https://doi.org/10.1039/C6NR00002A

45. C. Chen, Y. Wen, X. Hu, X. Ji, M. Yan et al., $\mathrm{Na}^{+}$intercalation pseudocapacitance in graphene-coupled titanium oxide enabling ultra-fast sodium storage and long-term cycling. Nat. Commun. 6, 6929 (2015). https://doi.org/10.1038/ ncomms 7929

46. J.A. Khan, C. Han, N.S. Shah, H.M. Khan, M.N. Nadagouda et al., Ultraviolet-visible light-sensitive high surface area phosphorous-fluorine-co-doped $\mathrm{TiO}_{2}$ nanoparticles for the degradation of atrazine in water. Environ. Eng. Sci. 31(7), 435-446 (2014). https://doi.org/10.1089/ees.2013.0486

47. D. Yang, Q. Zhao, L. Huang, B. Xu, N.A. Kumar, X.S. Zhao, Encapsulation of $\mathrm{NiCo}_{2} \mathrm{O}_{4}$ in nitrogen-doped reduced graphene oxide for sodium ion capacitors. J. Mater. Chem. A 6(29), 14146-14154 (2018). https://doi.org/10.1039/C8TA0 $3411 \mathrm{G}$

48. D. Yan, C. Yu, D. Li, X. Zhang, J. Li, T. Lu, L. Pan, Improved sodium-ion storage performance of $\mathrm{TiO}_{2}$ nanotubes by $\mathrm{Ni}^{2+}$ doping. J. Mater. Chem. A 4(28), 1107711085 (2016). https://doi.org/10.1039/C6TA04906K

49. L. Wang, G. Yang, J. Wang, S. Wang, C. Wang, S. Peng, W. Yan, S. Ramakrishna, In situ fabrication of branched $\mathrm{TiO}_{2} / \mathrm{C}$ nanofibers as binder-free and free-standing anodes for high-performance sodium-ion batteries. Small 15, 1901584 (2019). https://doi.org/10.1002/smll.201901584

50. G. Xu, L. Yang, Z. Li, X. Wei, P.K. Chu, Protein-assisted assembly of mesoporous nanocrystals and carbon nanotubes for self-supporting high-performance sodium electrodes. J. Mater. Chem. A 5(6), 2749-2758 (2017). https://doi. org/10.1039/C6TA09673E

51. G. Xu, Y. Tian, X. Wei, L. Yang, P.K. Chu, Free-standing electrodes composed of carbon-coated $\mathrm{Li}_{4} \mathrm{Ti}_{5} \mathrm{O}_{12}$ nanosheets and reduced graphene oxide for advanced sodium ion batteries. J. Power Sources 337, 180-188 (2017). https://doi. org/10.1016/j.jpowsour.2016.10.088

52. V. Augustyn, J. Come, M.A. Lowe, J.W. Kim, P.-L. Taberna, S.H. Tolbert, H.D. Abruña, P. Simon, B. Dunn, High-rate 
electrochemical energy storage through $\mathrm{Li}^{+}$intercalation pseudocapacitance. Nat. Mater. 12(6), 518 (2013). https:// doi.org/10.1038/nmat3601

53. L.F. Que, F.D. Yu, X.L. Sui, L. Zhao, J.G. Zhou, D.-M. Gu, Z.-B. Wang, Thermal-induced interlayer defect engineering toward super high-performance sodium ion capacitors. Nano Energy 59, 17-25 (2019). https://doi.org/10.1016/j. nanoen.2019.02.030

54. R. Yan, E. Josef, H. Huang, K. Leus, M. Niederberger et al., Understanding the charge storage mechanism to achieve high capacity and fast ion storage in sodium-ion capacitor anodes by using electrospun nitrogen-doped carbon fibers. Adv. Funct. Mater. 29, 1902858 (2019). https://doi.org/10.1002/ adfm. 201902858

55. J. Luo, F. Cong, C. Jin, H. Yuan, O. Sheng et al., Tunable pseudocapacitance storage of MXene by cation pillaring for high-performance sodium ion capacitors. J. Mater. Chem. A 6(17), 7794-7806 (2018). https://doi.org/10.1039/C8TA0 2068J

56. N.A. Kumar, J.-B. Baek, Doped graphene supercapacitors. Nanotechnology 26(49), 492001 (2015). https://doi. org/10.1088/0957-4484/26/49/492001 